○ Open Access Full Text Article

ORIGINAL RESEARCH

\title{
Intention to Care for COVID-19 Patients Among Nurses Working at Health Care Institutions of Debre Tabor Town, North Central Ethiopia
}

\author{
Binyam Minuye \\ Wubet Alebachew (D) \\ Melese Kebede \\ Sintayehu Asnakew \\ Demeke Mesfin Belay \\ College of Health Sciences, Debre Tabor \\ University, Debre Tabor, Ethiopia
}

Correspondence: Binyam Minuye Tel +25I92I574025

Email biniamminuye@yahoo.com
Background: Coronavirus disease 2019 (COVID-19) has caused many challenges for health care providers. Nurses meet patients with coronavirus disease and offer care for newly communicable diseases. Despite global and national efforts to prevent the spread, the outbreak is still on a rise, and studies on the health care behaviors of nurses were scarce in the study setting. Therefore, this study was intended in addressing nurses' intention to care for coronavirus disease 19 patients and its determinants among nurses working at Debre Tabor town Health Care Institutions, 2020.

Methodology: An institutional-based cross-sectional study was conducted among 163 nurses working at health care institutions of Debre Tabor Town, from June 01 to 15/2020. The data were collected using tools with a self-administration questionnaire adapted from the theory of planned behavior and different kinds of literatures. All nurses working at Debre Tabor health care institutions were included. Data were entered using Epi-data 4.2.0.0 statistical software, and analysis was done by Stata version 14 statistical software. Binary logistic regression model was used for analysis. Strength of association was measured using the odds ratio with $95 \% \mathrm{CI}$, and the level of significance was estimated at P-value $\leq 0.05$.

Results: Nurses' intention to care for COVID-19 patient was 59.5\% (95\% CI; 58.7:60.3). Having better working experience (adjusted odds ratio $(\mathrm{AOR})=2.3: 95 \% \mathrm{CI} ; 1.120,4.910$ ), caring experience for infectious disease $(\mathrm{AOR}=2.5 ; 95 \% \mathrm{CI}: 1.10,5.50)$, good perceived behavioral control $(\mathrm{AOR}=2.33 ; 95 \% \mathrm{CI}: 1.13,4.8)$, and subjective norms $(\mathrm{AOR}=2.14 ; 95 \%$ CI: $1.05,4.36$ ) were significantly associated with intention of caring behavior.

Conclusion: Nurses' intention to care for COVID-19 patients was low. Working experience, the experience of caring for infectious disease, self-efficacy, and subjective norm were independently related with nurses' caring intention. The government should work on improving nurse's confidence in disaster management, design disaster management nursing education, and frequent support of nurses.

Keywords: theory of planned behavior, coronavirus, nurse, intention to care, Ethiopia

\section{Background}

Corona Virus Disease has been a worldwide health problem issue ${ }^{1}$ manifested by signs/symptoms of fever, dry cough, fatigue, myalgia, dyspnea, diarrhea, and bilateral lung involvement with ground-glass opacity. ${ }^{2-4}$ Due to the great request for repeated attention for patients and closeness to respirational discharges, healthcare workers especially nurses ${ }^{5}$ have been a great threat of coronavirus infection. 
The nature of the infection and working behavior carries implications for nurse working conditions and personal safety that need to be recognized. ${ }^{6,7}$ Nurses are in charge of nursing care quality, have the greatest contact time with admitted patients. Compassionate caring; described by competency plus individualized considerate held via the expertise and carried out through proper behavior. ${ }^{8}$ However, unsuitable jobs, working for a longer time, inadequate properties, unfortunate administration, scarcity of human resources, and difficulty in crisis determination, management, and avoidance ${ }^{9}$ were some of the hindrances to provide appropriate care for patients in low-income nations.

In addition, caring for coronavirus infected patients at intensive care unit focused on providing circulatory, respirational, psychological, urinary, and digestive care plus checking. ${ }^{10}$ Different factors affect nursing care, ${ }^{11}$ personal susceptibilities for adjustment, threat prediction, fear, level of understanding on corona virus disease, ${ }^{12}$ the occurrence of death at the workplace, recognition of the condition's contagion, and casualty, ${ }^{13}$ negative belief, job stress, social pressures, ${ }^{14,15}$ normative beliefs, and subjective norms. ${ }^{16}$ Moreover, studies revealed that male Health care providers, medical doctors, permanent engagement, the consciousness of disease threat, supposed individual wellbeing, knowledge towards the COVID 19, rolespecific understanding, training on pandemic preparedness and response, and self-reliance individual performance ${ }^{17,18}$ increased willingness to work during the pandemic. So, safeguarding the health workforce through establishing a safe healthcare system ${ }^{19}$ has paramount importance.

As nurses have nearby interaction and participation in therapeutic measures, ${ }^{7}$ it is important to understand the beliefs underlying nurses' caring intention from a sound theoretical framework which can then update intervention strategies to encourage greater caring intention behavior.

The occurrence of deliberate behavior is the drive to accomplish that behavior. ${ }^{20}$ The Theory of Planned behavior (TPB) is grounded on the conventions that human beings are reasonable, made logical utilization of existing evidence, and reflect the effects of their activities before involving in a behavior. Performing the behavior is in direct relation with the strength of individuals' intention to implement the behavior. ${ }^{15}$ The intent of caring behavior has been predicted by the theory of planned behavior; attitude of the individuals' subjective norms, and selfefficacy (perceived behavioral control). ${ }^{21}$
During severe acute respiratory syndrome (SARS) pandemic health care workers confront whether to deliver care for patients or keeping individual well-being. ${ }^{15}$ To increase nurse ability to deliver appropriate care for COVID 19 patients in the study setting, take responsibility for caring diseased, and maximize the safety of nurses is important. As such, identifying the intention of nurses to care for COVID-19 patient could have a significant value for facilitating COVID-19 treatment and isolation centers. Hence, this study was intended at assessing nurses caring intention for COVID-19 patients and its determinants in Debre Tabor town, north-central Ethiopia; using TPB as a framework.

\section{Methodology Study Setting, Design, Period, and Population}

A cross-sectional study was conducted in Health Care Institutions of Debre Tabor town, June 01-15 2020. There are one Referral Hospital and four Health Centers. Nurses working in four health care organizations were the source population. An estimated 194 nurses were working in four health care institutions. All nurses working in Debre Tabor town health care institutions were included. Nurses who were not willing to provide written consent and annual leave were excluded.

\section{Sample Size Determination}

A single proportion formula was used to calculate the estimated sample size (n); by considering proportion (P) $=50 \%$, level of significance $(\mathrm{a}=0.05)$, and marginal of error $(\mathrm{D}=0.05)$

$$
\mathrm{n}=\frac{\left(\mathrm{Z}_{\mathrm{a} / 2}\right)^{2} \mathrm{P}(1-\mathrm{P})}{\mathrm{d}^{2}}=\frac{(1.96)^{2}(0.52)(0.48)}{(0.05)^{2}}=383.54 \sim 384
$$

Then $\mathrm{n}=\left(\mathrm{Z}^{\mathrm{a} / 2}\right)(\mathrm{pq}) / \mathrm{d}^{2}=384 \mathrm{n}=(1.96)^{2}$

After adding non response rate of $10 \%, n=423$

Reduction formula was used since the total population of $<10,000 . \mathrm{n}=\mathrm{no} /(1+(\mathrm{no}-1 / \mathrm{N}))$

$\mathrm{N}_{\text {final }}=130$ Where $\mathrm{n}=423$ and $\mathrm{N}$ was the estimated number of nurses (total population size, 194). Even if the sample size required is 130, we include all nurses (163) present at the time of the data collection period.

\section{Methods of Data Collection}

The data collection tool was adopted from the theory of planned behavior $^{15,21}$ and collected through self- 
administer method. The data collection tool has sociodemographic and economic factors, knowledge-related factors, attitude-related, subjective norm, and perceived control variables. The survey was conducted by four Bachelor of Science degree nurse data collectors and one master's supervisor. A total of 8 Likert scale questions were asked to assess nurses' intention of caring for COVID-19 patients. After computing the mean of the responses, the intention was grouped into two (positive and negative). Similarly, six questions were used to assess perceived control belief, five questions to assess normative belief, and ten questions to assess knowledge of COVID-19.

\section{Variables}

\section{Dependent Variables}

Intention to care (Positive, Negative)

Independent Variables

Socio-demographic and personal related variables (Age of nurses, Marital Status, Sex Income per month, Experience, training, place of work); Knowledge related to COVID 19; Attitude; Subjective norm, and perceived related factors.

\section{Operational Definitions}

Knowledgeable - if the score is greater than or equal to the average score.

Intention to care was considered by nurses' perception to care COVID-19 patient. Those having a score above or equal to the mean score have good intention of caring behavior.

Attitude towards caring for COVID-19 patients was measured using nurses' beliefs and assessment of behavior application.

Subjective norms - the nurses' normative beliefs in caring for COVID 19 patients, with the attention of others (such as parents, friends, siblings, a spouse, physician, coordinator nurse), and their inspiration to conform with the anticipations of their importance. ${ }^{22}$

Perceived behavioral control - perception of caring for COVID-19 patients' (easiness or difficulty).

\section{Data Quality Control}

One day of training was provided on administering the tool during data collection, and the ethical aspect. The completeness of each tool was checked daily. Data were entered by two data clerks and a cross-check was done using Stata software.

\section{Method of Data Analysis}

EPI-Data statistical software version 4.2.0.0 was used for data entry and STATA Version 14 statistical software for analysis. The model used for analysis was Binary logistic regression. Those variables with a p-value of less than 0.25 during bi-variable analysis were taken to multivariable analysis. Statistical significance was declared for variables with a p-value of less than 0.05 during multivariable analysis. Text, figures, and tables were used for data presentation.

\section{Result}

\section{Socio-Demographic Factors}

Overall, 163 nurses were involved. Nearly, 62\% (101) of nurses were in the age group of less than or equal to 31 years, with a mean $( \pm \mathrm{SD})$ of $31.7 \pm 5.7$ years. About, $72.4 \%$ (118) were married and BSc in educational level. The majority, 94.5\% (154) were orthodox Christian in religion. One hundred eighty-two, $50.3 \%$ of nurses had a monthly earning of less than 5727 Ethiopian Birr. More than half, $57.7 \%$ (94) were working in the ward, followed by $27.6 \%$ (45) in outpatient (Table 1).

\section{Perceived Behavioral Control (Self-Efficacy)}

A total of 6 Questionnaires with a 5-point Likert scale were asked to assess the perceived control belief of nurses. Those six questions were computed and perceived control grouped into two using the mean score as a cut of point (Positive and negative control). More than half, 54\% (88) of nurses had negative perceived behavioral control. Moreover, 61\% (99) of nurses had positive subjective norms.

\section{Intention to Care for COVID-19}

A total of 163 nurses functioning at health care institutions of Debre Tabor town were involved. Eight Likert scale questionnaires were used for assessing nurses' intention of caring behavior. The nurse's intention to care for coronavirus infected was, $59.5 \%$ (95\% CI; 58.70 to 60.30$)$.

\section{Factors Associated with Nurses Caring Intention Behavior}

A binary logistic regression model was used for analysis. Sex, working experience, the experience of caring for infectious disease cases, participating in COVID-19 related training, knowledge of COVID 19, perceived 
Table I Socio-Demographic Characteristics of the Study Participants'

\begin{tabular}{|c|c|}
\hline Socio-Demographic Factors & Frequency (\%) \\
\hline \multicolumn{2}{|l|}{ Gender } \\
\hline Male & $85(52.15)$ \\
\hline Female & $78(47.85)$ \\
\hline \multicolumn{2}{|l|}{ Age } \\
\hline$\leq 31$ years & $101(61.96)$ \\
\hline$>31$ years & $62(38.04)$ \\
\hline \multicolumn{2}{|l|}{ Marital status } \\
\hline Unmarried & $40(24.54)$ \\
\hline Married & II (72.39) \\
\hline Divorced/separated & $5(3.07)$ \\
\hline \multicolumn{2}{|l|}{ Religion } \\
\hline Orthodox & I54 (94.48) \\
\hline Others & $9(5.52)$ \\
\hline \multicolumn{2}{|l|}{ Level of education } \\
\hline Diploma & $4 \mid(25.3 I)$ \\
\hline BSc & $117(72.22)$ \\
\hline MSc & $4(2.47)$ \\
\hline \multicolumn{2}{|l|}{ Monthly income } \\
\hline$\leq 5727$ ETB & $\mid 82(50.3 \mid)$ \\
\hline$>5727$ ETB & $81(49.69)$ \\
\hline \multicolumn{2}{|l|}{ Working experience } \\
\hline$<3$ years & $6(3.68)$ \\
\hline $3-6$ years & $77(47.24)$ \\
\hline$>6$ years & $80(49.08)$ \\
\hline \multicolumn{2}{|l|}{ Working unit } \\
\hline Emergency & $24(14.72)$ \\
\hline Ward & $94(57.67)$ \\
\hline Outpatient & $45(27.61)$ \\
\hline
\end{tabular}

Note: Others: Muslim, catholic and protestant. Abbreviation: ETB, Ethiopian birr.

behavioral control, and subjective norm were associated with nurses caring intention during bi-variable analysis. Whereas, in multivariable analysis; working experience, the experience of caring for infectious disease perceived behavioral control (self-efficacy), and subjective norm were statistically significant (Table 2).

The study showed that nurses who had 8 years and above working experience were 2.33 times more likely to have a positive intention of caring for COVID-19 patients than nurses who had working experience of fewer than eight years (adjusted odds ratio ( $\mathrm{AOR}=2.3,95 \% \mathrm{CI}$ : 1.1,4.9)). Likewise, the odd of positive intention to care was 2.45 times more likely among experienced nurses of caring infectious disease cases than those without experience ( $\mathrm{AOR}=2.45 ; 95 \% \mathrm{CI}: 1.09,5.49)$. In addition, nurses who had positive perceived control were 2.33 times more likely to have a positive intention of caring for COVID-19 patients than nurses who had negative perceived control $(\mathrm{AOR}=2.33$; 95\% CI: 1.13, 4.78). Those care providers with positive subjective norms were 2.14 times more probably for the positive caring intention in contrast to nurses with negative subjective norms $(\mathrm{AOR}=2.14 ; 95 \% \mathrm{CI}: 1.05,4.36)$

\section{Discussion}

COVID-19 is an infectious disease that requires frequent patient care from health care providers. Since nurses comprise the larger proportion HCPs and the nature of the contagion carries implications for nurse working conditions and personal safety to be recognized. As such, identifying the intention of nurses had its contribution in reducing the burden of the pandemic.

The current study showed that the intention to care for COVID-19 patients was $59.5 \%$. The finding was higher than studies conducted in Taiwan, $42.7 \%,{ }^{23}$ and Korea $55.1 \% .^{22}$ The possible reasons could be previous studies were conducted during the SARS pandemic. But, lower than studies in Australia, 62\%, ${ }^{24}$ and Portland, 90\%. ${ }^{25}$ This discrepancy could be due to differences in sample size and study setting. The study conducted in Australia was conducted among 83 nurses working in the intensive care units. The second study was conducted during the influenza outbreak. Moreover, the discrepancy could be in relation with difference in the health care policy, previous exposure to pandemics, nurses' welfare, preparedness, and economical level of the country.

The study showed that nurses who had eight years and above working experience were 2.33 times more likely to have positive intentions of caring for COVID-19 patients than nurses who had working experience of fewer than eight years. This is supported by other findings from China and Japan. ${ }^{26-28}$ This might be due to because of working experience increase the knowledge, and skill of nurses caring for patients. Moreover, professional experience increases job satisfaction. ${ }^{29}$ Less experienced nurses were displeased with their payment, workload, financial benefit, and the opportunity to continue their education. ${ }^{30}$

The odds of positive intention to care was 2.45 times more likely among experienced nurses on infectious disease than nurses without such experience. This finding is in agreement with previous studies conducted in China and 
Table 2 Factors Associated with Nurses' Caring Intention of Coronavirus 2019 Patients

\begin{tabular}{|c|c|c|c|c|c|}
\hline \multirow[t]{2}{*}{ Variables } & \multicolumn{2}{|c|}{ Intention to Care } & \multirow[t]{2}{*}{ COR } & \multirow[t]{2}{*}{ AOR } & \multirow[t]{2}{*}{ P-value } \\
\hline & $\begin{array}{l}\text { Positive } \\
\text { No. (\%) }\end{array}$ & $\begin{array}{l}\text { Negative } \\
\text { No. (\%) }\end{array}$ & & & \\
\hline \multicolumn{6}{|l|}{ Sex } \\
\hline $\begin{array}{l}\text { Female } \\
\text { Male }\end{array}$ & $\begin{array}{l}40(4 I .2) \\
57(58.8)\end{array}$ & $\begin{array}{l}38(57.6) \\
28(42.4)\end{array}$ & $\begin{array}{l}\text { Ref. } \\
1.93(1.03, \\
3.65)\end{array}$ & $\begin{array}{l}\text { Ref. } \\
\text { I.35 (0.64, } \\
2.85)\end{array}$ & \\
\hline \multicolumn{6}{|c|}{ Working experience } \\
\hline $\begin{array}{l}\leq 8 \text { years } \\
>8 \text { years }\end{array}$ & $\begin{array}{l}71(73.2) \\
26(26.8)\end{array}$ & $\begin{array}{l}34(51.5) \\
32(48.5)\end{array}$ & $\begin{array}{l}2.57 \text { (I.33, } \\
4.97) \\
\text { Ref }\end{array}$ & $\begin{array}{l}2.33(1.12, \\
4.91) \\
\text { Ref }\end{array}$ & 0.026 \\
\hline \multicolumn{6}{|c|}{ Experience caring for infectious disease pts. } \\
\hline $\begin{array}{l}\text { Yes } \\
\text { No }\end{array}$ & $\begin{array}{l}80(82.5) \\
17(17.5)\end{array}$ & $\begin{array}{l}4 I(62.1) \\
25(37.9)\end{array}$ & $\begin{array}{l}2.86(1.39,5.9) \\
\text { Ref. }\end{array}$ & $\begin{array}{l}2.45 \text { ( } 1.09, \\
5.49) \\
\text { Ref. }\end{array}$ & 0.029 \\
\hline \multicolumn{6}{|c|}{ Participating in COVID I9-related training } \\
\hline $\begin{array}{l}\text { Yes } \\
\text { No }\end{array}$ & $\begin{array}{l}34(35.1) \\
63(64.9)\end{array}$ & $\begin{array}{l}13(19.7) \\
53(80.3)\end{array}$ & $\begin{array}{l}2.2(1.05,4.59) \\
\text { Ref. }\end{array}$ & $\begin{array}{l}\text { I.29 (0.57, } \\
2.93) \\
\text { Ref. }\end{array}$ & \\
\hline \multicolumn{6}{|c|}{ Knowledge of COVID-19 } \\
\hline $\begin{array}{l}\text { Good } \\
\text { Poor }\end{array}$ & $\begin{array}{l}58(59.8) \\
39(40.2)\end{array}$ & $\begin{array}{l}26(39.4) \\
40(60.6)\end{array}$ & $\begin{array}{l}2.29 \text { (I.2I, } \\
4.34) \\
\text { Ref. }\end{array}$ & $\begin{array}{l}\text { I.66 }(0.82,3.4) \\
\text { Ref. }\end{array}$ & \\
\hline \multicolumn{6}{|c|}{ Perceived behavioral control (self- efficacy) } \\
\hline Negative & $\begin{array}{l}54(55.7) \\
43(44.3)\end{array}$ & $\begin{array}{l}21(31.8) \\
45(68.2)\end{array}$ & $\begin{array}{l}2.69(1.4,5.18) \\
\operatorname{Ref}\end{array}$ & $\begin{array}{l}2.33(1.13, \\
4.78) \\
\text { Ref }\end{array}$ & 0.021 \\
\hline \multicolumn{6}{|c|}{ Normative belief } \\
\hline Negative & $\begin{array}{l}66(68.0) \\
31(32.0)\end{array}$ & $\begin{array}{l}33(50.0) \\
33(50.0)\end{array}$ & $\begin{array}{l}2.13(1.12, \\
4.05) \\
\text { Ref }\end{array}$ & $\begin{array}{l}2.14(1.05, \\
4.36) \\
\text { Ref }\end{array}$ & 0.036 \\
\hline
\end{tabular}

Note: Significant: P-value $\leq 0.05$.

Abbreviation: Ref, reference.

South Korea. ${ }^{28,31}$ The possible reasons could be better experience in caring for infectious disease, the better to practice preventive practice with confidence, and increased if provided with adequate personal protective equipment. In Korea, almost half of nurses had exposure of caring infectious disease cases, and twenty-six percent had the experience of caring for severe acute respiratory syndrome infected patients. ${ }^{15}$

Nurses who had positive perceived control were 2.33 times more likely to have positive intention of caring for COVID-19 patients than nurses who had negative perceived control. The result of the current study is similar to other 
findings in Korea and Israel. ${ }^{15,32-34}$ This could be positive emotion decrease psychological distress, fear, and anxiety, ${ }^{35,36}$ in turn, improve nurses' working intention. Moreover, perceived behavioral control expectations improve actual control of nurses' skills. Similarly, those nurses who had positive subjective norms were 2.14 times more likely to have positive intention to care than nurse with negative subjective norms. The finding is similar with findings from Korea and United States of America. ${ }^{32,37}$ In contrast, the finding from Korea revealed that subjective norms were not associated with nursing intention to care. ${ }^{22}$ This could be due to those with normative control intend to execute more beneficial behaviors. The paper has its own limitation. Hence, the data was collected during the lockdown of the country, the data was not triangulated with the qualitative part, and conducted in a limited setting. Moreover, it does not show cause effect relationship. Therefore, researcher should work on qualitative analysis of identifying motivating factors, barriers of intention to care during pandemic season, and what should be taken for tackling future pandemics.

\section{Conclusions}

In the current study, the intention to care for corona Virus disease patients was low. Working experience, having experience of caring for infectious disease, subjective norm, and perceived control were independently related to nurses' caring intention behavior for COVID 19 patients. The government should work in providing COVID 19 related pieces of training, improve nurse's confidence in disaster management, design disaster management nursing education, and frequent support of nurses will have an important input in improving nurse's intention to work during the pandemic.

\section{Abbreviations}

AOR, Adjusted Odds Ratio; CI, Confidence Interval; COR, Crude Odds Ratio; COVID-19, Corona Virus Disease 2019; IRERC, Institutional Research Ethics Review Committee; TPB, Theory of Planned Behaviour; SARS, Severe Acute respiratory syndrome.

\section{Data Sharing Statement}

All relevant data are within the manuscript.

\section{Ethical Approval and Consent to Participate}

Ethical clearance was secured from Debre Tabor University, College of Health Sciences Health Research Ethical Review committee. Information regarding the purpose of the study, voluntary nature of participants, risk imposed due to involvement presented in the information section of the survey. Informed written consent was taken. Confidentiality of the information was maintained and the data were recorded anonymously throughout the study. This study was conducted in accordance with the Declaration of Helsinki.

\section{Acknowledgments}

The authors' gratitude goes to data collectors and nurses.

\section{Author Contributions}

All authors made substantial contributions to conception and design, acquisition of data, or analysis and interpretation of data; took part in drafting the article or revising it critically for important intellectual content; agreed to submit to the current journal; gave final approval of the version to be published; and agree to be accountable for all aspects of the work.

\section{Funding}

There is no funding to report.

\section{Disclosure}

The authors report no conflicts of interest in this work.

\section{References}

1. Worldometer. COVID-19 Coronavirus Pandemic; 2020. Available from: https://www.worldometers.info/coronavirus/. Accessed May 11, 2020.

2. Lai -C-C, Shih T-P, Ko W-C, Tang H-J, Hsueh P-R. Severe acute respiratory syndrome coronavirus 2 (SARS-CoV-2) and corona virus disease-2019 (COVID-19): the epidemic and the challenges. Int $J$ Antimicrob Agents. 2020;55(3):105924. doi:10.1016/j. ijantimicag.2020.105924

3. Huh S. How to train the health personnel for protecting themselves from novel coronavirus (COVID-19) infection during their patient or suspected case care. J Educ Eval Health Prof. 2020;17:10. doi:10.3352/jeehp.2020.17.10

4. Guan W-J, Ni Z-Y, Hu Y, et al. Clinical characteristics of 2019 novel coronavirus infection in China. MedRxiv. 2020.

5. Matsuishi K, Kawazoe A, Imai H, et al. Psychological impact of the pandemic (H1N1) 2009 on general hospital workers in Kobe. Psychiatry Clin Neurosci. 2012;66(4):353-360. doi:10.1111/j.14401819.2012.02336.x

6. Millar RC. Nursing a patient with Covid-19 infection. Tasman Med J. 2020;1(1).

7. Health AIo, Welfare. Health and community services labour force 2006. Canberra: AIHW; 2009.

8. Izumi S, Baggs JG, Knafl KA. Quality nursing care for hospitalized patients with advanced illness: concept development. Res Nurs Health. 2010;33(4):299-315. doi:10.1002/nur.20391

9. Darega B, Dida N. Perceived quality of nursing cares practices in inpatient Departments of Bale Zone Hospitals, Oromiya Regional State, Southeast Ethiopia Facility-Based Cross Sectional Study. Qual Prim Care. 2016;24(1). 
10. Lopez V, Chan KS, Wong YCJ. Nursing care of patients with severe acute respiratory syndrome in the intensive care unit: case reports in Hong Kong. Int J Nurs Stud. 2004;41(3):263-272. doi:10.1016/ S0020-7489(03)00137-8

11. Grol R, Wensing M. What drives change? Barriers to and incentives for achieving evidence-based practice. Med J Aust. 2004;180:S57S60. doi:10.5694/j.1326-5377.2004.tb05948.x

12. Simione L, Gnagnarella C. Differences between health workers and general population in risk perception, behaviors, and psychological distress related to COVID-19 spread in Italy. Front Psychol. 2020;11:2166. doi:10.3389/fpsyg.2020.02166

13. Al Otair H, Temsah M, Al-Eyadhy A, Alsubaie S, Azfar M. Anxiety and work avoidance among intensive care workers during an influenza A/H1N1 outbreak. J Community Med Health Educ. 2017;7 (515):2161-0711.1000515.

14. Sauls DJ. Nurses' attitudes toward provision of care and related health outcomes. Nurs Res. 2007;56(2):117-123. doi:10.1097/01. NNR.0000263972.54619.4a

15. Kim CJ, Yoo HR, Yoo MS, Kwon BE, Hwang KJ. Attitude, beliefs, and intentions to care for SARS patients among Korean clinical nurses: an application of theory of planned behavior. $J$ Korean Acad Nurs. 2006;36(4):596-603. doi:10.4040/jkan.2006.36.4.596

16. Javadi M, Kadkhodaee M, Yaghoubi M, Maroufi M, Shams A. Applying theory of planned behavior in predicting of patient safety behaviors of nurses. Mater Sociomed. 2013;25(1):52-55. doi:10.5455/msm.2013.25.52-55

17. Aoyagi Y, Beck CR, Dingwall R, Nguyen-Van-Tam JS. Healthcare workers' willingness to work during an influenza pandemic: a systematic review and meta-analysis. Influenza Other Respi Viruses. 2015;9(3):120-130. doi:10.1111/irv.12310

18. Devnani M. Factors associated with the willingness of health care personnel to work during an influenza public health emergency: an integrative review. Prehosp Disaster Med. 2012;27(6):551-566. doi:10.1017/S1049023X12001331

19. Yujeong Kim R. Nurses' experiences of care for patients with Middle East respiratory syndrome-coronavirus in South Korea. Am J Infect Control. 2018;46:781-787. doi:10.1016/j.ajic.2018.01.012

20. Ajzen I. The theory of planned behavior. Organ Behav Hum Decis Process. 1991;50(2):179-211. doi:10.1016/0749-5978(91)90020-T

21. Ajzen I Constructing a TPB questionnaire: conceptual and methodological considerations; 2002.

22. Lee J, Kang SJ. Factors influencing nurses' intention to care for patients with emerging infectious diseases: application of the theory of planned behavior. Nurs Health Sci. 2020;22(1):82-90. doi:10.1111/nhs.12652

23. Ko N-Y, Feng M-C, Chiu D-Y, Wu M-H, Feng J-Y, Pan S-M. Applying theory of planned behavior to predict nurses' intention and volunteering to care for SARS patients in southern Taiwan. Kaohsiung J Med Sci. 2004;20(8):389-398. doi:10.1016/S1607-551X(09)70175-5

24. Lord H, Loveday C, Moxham L, Fernandez R. Effective communication is key to intensive care nurses' willingness to provide nursing care amidst the COVID-19 pandemic. Intensive Crit Care Nurs. 2021;62:102946. doi:10.1016/j.iccn.2020.102946
25. Martin SD, Brown LM, Reid WM. Predictors of nurses' intentions to work during the 2009 influenza A (H1N1) pandemic. Am J Nurs. 2013;113(12):24-31. doi:10.1097/01.NAJ.0000438865.22036.15

26. Chen H, Li G, Li M, Lyu L, Zhang T. A cross-sectional study on nurse turnover intention and influencing factors in Jiangsu Province, China. Int $J$ Nurs Sci. 2018;5(4):396-402. doi:10.1016/j. ijnss.2018.09.012

27. Eltaybani S, Noguchi-Watanabe M, Igarashi A, Saito Y, YamamotoMitani N. Factors related to intention to stay in the current workplace among long-term care nurses: a nationwide survey. Int J Nurs Stud. 2018;80:118-127. doi:10.1016/j.ijnurstu.2018.01.008

28. Li J, Li P, Chen J, Ruan L, Zeng Q, Gong Y. Intention to response, emergency preparedness and intention to leave among nurses during COVID-19. Nurs Open. 2020;7(6):1867-1875. doi:10.1002/nop2.576

29. Masum AKM, Azad MAK, Hoque KE, Beh L-S, Wanke P, Arslan Ö. Job satisfaction and intention to quit: an empirical analysis of nurses in Turkey. PeerJ. 2016;4:e1896. doi:10.7717/peerj.1896

30. Delobelle P, Rawlinson JL, Ntuli S, Malatsi I, Decock R, Depoorter AM. Job satisfaction and turnover intent of primary healthcare nurses in rural South Africa: a questionnaire survey. J Adv Nurs. 2011;67(2):371-383. doi:10.1111/j.1365-2648.2010.05496.x

31. Oh N, Hong N, Ryu DH, Bae SG, Kam S, Kim K-Y. Exploring nursing intention, stress, and professionalism in response to infectious disease emergencies: the experience of local public hospital nurses during the 2015 MERS outbreak in South Korea. Asian Nurs Res. 2017;11(3):230-236. doi:10.1016/j.anr.2017.08.005

32. Talbot A-L, Dorrian J, Chapman J. Using the Theory of Planned Behaviour to examine enrolled nursing students' intention to care for patients with alcohol dependence: a survey study. Nurse Educ Today. 2015;35(11):1054-1061. doi:10.1016/j.nedt.2015.05.017

33. Shapira S, Friger M, Bar-Dayan Y, Aharonson-Daniel L. Healthcare workers' willingness to respond following a disaster: a novel statistical approach toward data analysis. BMC Med Educ. 2019;19 (1):1-12. doi:10.1186/s12909-019-1561-7

34. Choi HS, Lee J-E. Hospital nurses' willingness to respond in a disaster. J Nurs Adm. 2021;51(2):81-88. doi:10.1097/ NNA.0000000000000974

35. Labrague LJ, de Los Santos JAA. Fear of Covid-19, psychological distress, work satisfaction and turnover intention among frontline nurses. J Nurs Manag. 2020.

36. Xiong H, Yi S, Lin Y. The psychological status and self-efficacy of nurses during COVID-19 outbreak: a cross-sectional survey. Inquiry. 2020;57:0046958020957114.

37. Connor SB. Factors associated with the intention of health care personnel to respond to a disaster. Prehosp Disaster Med. 2014;29 (6):555. doi:10.1017/S1049023X14001186
Risk Management and Healthcare Policy

\section{Publish your work in this journal}

Risk Management and Healthcare Policy is an international, peerreviewed, open access journal focusing on all aspects of public health, policy, and preventative measures to promote good health and improve morbidity and mortality in the population. The journal welcomes submitted papers covering original research, basic science, clinical \& epidemiological studies, reviews and evaluations, guidelines, expert opinion and commentary, case reports and extended reports. The manuscript management system is completely online and includes a very quick and fair peer-review system, which is all easy to use. Visit http://www.dovepress.com/testimonials.php to read real quotes from published authors. 